\title{
Pendampingan Legalitas Usaha Mikro Kecil Dan Menengah Melalui Sistem Online Single Submission di Desa Lemahbang Kecamatan Sukorejo
}

\author{
Nurma Yuwita1), Sri astutik2), siti badriyatul'3), sri rahayu ${ }^{4)}$ \\ Universitas Yudharta \\ 1)nurma@yudharta.ac.id, 2)astutiksri2412@gmail.com, \\ 3)anggitrahayu45@gmail.com, ${ }^{4}$ sitibadriya99@gmail.com
}

\begin{abstract}
Abstrak. Pendampingan legalitas tentang Pendaftaran Izin Usaha Mikro Kecil (IUMK) di desa Lemahbang melalui Sistem Online Single Submission (OSS) berdasarkan Peraturan Pemerintah Nomor 24 Tahun 2018 ini, berangkat dari kurangnya sosialisasi dan edukasi kepada pelaku UMKM. Pelaksanaan pengabdian masyarakat dalam bentuk pendampingan legalitas mikro kecil dan menengah kepada sejumlah 40 pelaku UMKM di desa Lemahbang. Tingkat antusiasme peserta cukup tinggi dimana peserta banyak mengajukan pertanyaan seputar legalitas usaha dan berminat untuk mengurus legalitas usahanya. Pengabdian masyarakat ini bertujuan untuk meningkatkan kesadaran hukum pelaku UMKM untuk mengurus legalitas usahanya. Metode peningkatan kesadaran hukum dengan memberikan pendampingan. Adapun materi sosialisai meliputi UU No. 20 Tahun 2008 tentang UMKM dan Perpres No 98 Tahun 2014,Peraturan Pemerintah Nomor 24 Tahun 2018 tentang Pelayanan Perizinan Berusaha Terintegrasi Secara Elektronik/Online Single Submission (OSS). Pelaku Usaha Mikro, Kecil, dan Menengah sebagai salah satu pelaku pembangunan ekonomi di daerah perlu diberdayakan melalui pengembangan sumber daya manusia, dukungan permodalan, produksi dan produktifitas, perlindungan usaha, pengembangan kemitraan, jaringan usaha dan pemasaran serta legalitas usahanya melalui Online Single Submission (OSS). Hasil pendampingan menunjukkan peningkatan pemahaman dan kesadaran hukum UMKM untuk mengurus legalitas usahanya.
\end{abstract}

Kata kunci : Pendampingan, Legalitas, Surat ijin usaha mikro kecil (I-UMK)

\begin{abstract}
Legal assistance regarding the Registration of Micro Small Business Permits (IUMK) in Lemahbang village through the Online Single Submission System (OSS) based on Government Regulation Number 24 of 2018, departing from the lack of socialization and education to MSME actors. Implementation of community service in the form of micro, small and medium legal assistance to a number of 40 MSME actors in Lemahbang village. The level of enthusiasm of the participants was quite high where participants asked many questions about the legality of their business and were interested in taking care of the legality of their business. Method of increasing legal awareness by providing assistance. The material for socialization includes Law no. 20 of 2008 concerning MSMEs and Presidential Regulation No. 98 of 2014, Government Regulation Number 24 of 2018 concerning Integrated Electronic Business Licensing Services/Online Single Submission (OSS). Micro, Small, and Medium Enterprises as one of the actors of economic development in the regions need to be empowered through human resource development, capital support, production and productivity, business protection, partnership development, business networks and marketing as well as business legality through Online Single Submission (OSS). ). The results of the assistance show an increase
\end{abstract}




\section{Khidinatuina \\ Jurnal Penelitian dan Pengabdian Hepada Masularahat}

Institut Agama Islam Sunan Kalijogo Malang

P-ISSN: 2721-9607/ E-ISSN: 2721-947X

Volume 2 Nomor 1 Juli 2021

in understanding and legal awareness of MSMEs to take care of the legality of their business.

Keywords: Mentoring, Legality, Micro and Small Business License (I-UMK)

\section{PENDAHULUAN}

UMKM adalah singkatan dari Usaha Mikro, Kecil, dan Menengah. UMKM diatur berdasarkan UU Nomor 20 tahun 2008 tentang Usaha Mikro, Kecil,dan Menengah. UKM memiliki peranan yang sangat vital di dalam pembangunan dan pertumbuhan ekonomi, tidak hanya di Negara-negara berkembang seperti Indonesia, tetapi juga di Negara-negara maju. Di Indonesia, peranan UMKM selain berperan dalam pertumbuhan pembangunan dan ekonomi, UMKM juga memiliki peranan yang sangat penting dalam mengatasi pengangguran. Tumbuhnya usaha mikro menjadikannya sebagai sumber pertumbuhan kesempatan kerja dan pendapatan. Dengan banyak menyerap tenaga kerja, berarti UMKM juga memiliki peran strategis dalam upaya pemerintah dalam memerangi kemiskinan dan pengangguran.

Salah satu aspek yang sangat penting untuk pengembangan Usaha Kecil dan Menengah (UKM) adalah legalitas usaha. Legalitas usaha melalui perizinan sangat penting bagi UKM untuk dapat mepermudah pelaku usaha mengakses permodalan dalam mengembangkan usahanya dan bersaing dengan pelaku usaha lainnya.

Maka Guna Menindaklanjuti legalasi pada 15 September 2014 Presiden menerbitkan Peraturan Presiden (Perpres) Republik Indonesia Nomor 98 Tahun 2014 Tentang Perizinan untuk Usaha Mikro dan Kecil ini memuat bahwa kegiatan usaha mikro dan kecil sebagai salah satu usaha ekonomi kerakyatan yang bergerak dalam usaha perdagangan sektor informal perlu dilakukan pemberdayaan untuk meningkatkan dan mengembangkan kegiatan usaha dan perekonomian masyarakat bahwa dalam rangka meningkatkan dan mengembangkan perekonomian masyarakat melalui kegiatan usaha mikro dan kecil, maka perlu adanya akses yang sederhana, mudah dan cepat dalam proses perizinan sebagai legalitas hukum untuk mendapatkan kepastian dan perlindungan dalam berusaha.

Di Desa Lemahbang Kecamatan Sukorejo Kurang lebih terdapat 40 usaha yang memiliki usaha mikro dan kecil diantaranya produksi tempe,chattereing,dsb.Namun problematika yang ada di desa Lemahbang masih banyak dari para pelaku usaha mikro belum memiliki surat izin mikro dan kecil (I-UMK). Hal ini dengan mendukung program pemerintah pusat juga pemerintah daerah dalam memajukan ekonomi kerakyatan dan mengembangkan usaha mikro 
dan kecil yang menjadi program pada kabinet kerja.Pada tingkat sosialisasi kami memberikan pemahaman terkait pentingnya memiliki surat izin usaha mikro dan kecil dan fungsi Surat izin usaha mikro dan kecil itu sendiri, kami juga memberikan suatu solusi pada masyarakat agar bisa mempuyai surat izin untuk usaha mikro dan kecil agar masyarakat Desa Lemahbang yang memiliki usaha bisa memiliki legalitas dalam usahanya.

\section{METODE PELAKSANAAN KEGIATAN}

Kegiatan pengabdian masyarakat oleh kelompok KKN ( Kuliah kerja Nyata ) 9 universitas yudharta pasuruan Pemecahan permasalahan pendaftaran IUMK di Desa Lemahbang dalam meningkatkan pemahaman pentingnya legalitas usaha dan bagaimana tata cara pengurusannya dilakukan dengan beberapa pendekatan yang dilakukan secara bersama-sama, yaitu: 1) Ceramah dan tutorial, metode ini dilakukan pada kegiatan pendampingan. Tim pelaksana pengabdian memberikan materi dengan metode ceramah disertai dengan tanya jawab serta tutorial untuk membantu peserta pengabdian. 2) Berbasis small group discussion, yaitu metode small group discussion adalah suatu cara mengajar yang dibagi menjadi beberapa kelompok. Setiap kelompok dibagi menjadi tiga sampai dengan lima orang (Fatimah, Kartika, \& Niyartama, 2012). Mereka bekerja sama dalam memecahkan masalah atau mempersiapkan syarat-syarat yang harus dilengkapi untuk memperoleh IUMK., setelah diadakan observasi dan pendampingan. 3) Komprehensif, seluruh kegiatan pengabdian masyarakat dilakukan secara serentak terkait dengan Sumber Daya manusia (SDM), proses belajar, pelatihan dan pendampingan tenaga pengajar dan dibantu pendamping dari dinas perizinan usaha dagang kabupaten Pasuruan yang professional, 4) Learning by doing berbasis output. Hasil pengabdian yang dilakukan dengan proses pendampingan diharuskan menghasilkan terbitnya IUMK untuk masing-masing peserta pendampingan.Selanjutnya, ketiga metode di atas diimplementasikan dalam empat tahapan, yaitu Observasi, Penyuluhan tentang I-UMK dan pendampingan pendaftaran atau pelaksanaan kegiatan. Pelaksanaan kegiatan pengabdian dilakukan dalam bulan Agustus 2020. Mitra adalah pelaku UMKM desa Lemahbang. Adapun tahap-tahap yang kami lakukan pada pengabdian ini meliputi:

\section{a. Observasi Kegiatan}

Pada tahap awal kegiatan pengabdian kami melakukan observasi awal sebagai bahan pengabdian kami. Selain observasi kami melakukan wawancara dan audensi kepada kepala dusun masing-masing desa Lemahbang. Dari hasil observasi yang kami lakukan 


\section{Khidinatuna \\ Jurnal Penelitian dan Pengabdian Hepada Masularahat}

Institut Agama Islam Sunan Kalijogo Malang

P-ISSN: 2721-9607/ E-ISSN: 2721-947X

Volume 2 Nomor 1 Juli 2021

diperoleh data bahwa UMK di desa Lemahbang sebagian besar masih belum memiliki IUMK. Kemudian disepakati untuk mengadakan penyuluhan hukum dan pendampingan dengan peserta perwakilan dari setiap dusun yang ada.

b. Penyuluhan Tentang I-UMK dan Pendampingan

Berdasarkan permasalahan yang ada maka pengabdian kami lakukan dengan beberapa kegiatan, salah satunya adalah penyuluhan hukum dan pendampingan. Penyuluhan hukum menggunakan metode ceramah dan tanya jawab.

c. Pelaksanaan Kegiatan Pendampingan

Pada rangkaian kegiatan pengabdian yang diadakan adalah dalam rangka memacu motivasi pelaku UMKM untuk mendaftarkan izin usahanya dan memperoleh IUMK. Dengan demikian, dari rangkaian kegiatan pengabdian kami mengadakan pendampingan dan bimbingan teknis pendaftaran yang dibantu langsung oleh petugas dari dinas perizinan usaha dagang kabupaten Pasuruan.

Berdasarkan informasi yang diperoleh dari hasil observasi kelompok kkn 9 di Desa Lemahbang ada lebih dari 40 UMKM yang belum memiliki surat ijin. Ada 30 pemilik ukm yang berniat untuk mengurus ijin usaha mikro dan kecil (IUMK). Pendampingan pengurusan surat ijin usaha ini kami lakukan sampai dengan terbitnya surat IUMK tersebut.

1. Adapun Syarat-syarat untuk mendapatkan I-UMK adalah:

1. Surat pengantar dari RT atau RW terkait lokasi usaha/

2. Fotokopi Kartu Tanda Penduduk (KTP)

3. Fotokopi Kartu keluarga (KK)

4. Pas foto terbaru berwarna ukuran $4 \times 6$ (2 lembar)

5. Mengisi formulir I-UMK yang telah trersedia.

(Sumber: Permendagri No. 83 Tahun 2014).

2. Tahapan pengajuan perizinan secara online melalui 3 tahap yaitu:

1. membuat akun OSS Pemohon mengunjungi website https://www.oss.go.id/oss/., klik tombol "Daftar" di kanan atas, mengisi formulir yang ada di layar.

2. Masuk ke akun OSS dan mengisi data.

3. Mengunduh Nomor Induk Berusaha (NIB) dan IUMK.

Sumber: Permendagri No. 83 Tahun 2014 dan https://www.oss.go.id/oss/ 


\section{Khidinatuina \\ Jurnal Penelitian dan Pencabdian Hepada Masularahat}

Institut Agama Islam Sunan Kalijogo Malang

P-ISSN: 2721-9607/ E-ISSN: 2721-947X

Volume 2 Nomor 1 Juli 2021

\section{HASIL DAN PEMBAHASAN}

\section{Ceramah dan tutorial}

Dalam metode ini tim pengabdian memberikan materi dan pemahaman terkait pentingnya legalitas usaha mikro kecil dan menengah, Serta tutorial dan persyaratan dalam pendaftaran surat ijin usaha mikro kecil dan menengah, Metode yang kami berikan dengan menggunakan ceramah dan tanya jawab serta tutorial dengan peseta pengabdian, Metode ini dilakukan pada kegiatan pendampingan legalitas usaha mikro kecil dan menengah pada masyarakat Desa Lemahbang yang memiliki usaha Mikro kecil dan menengah.

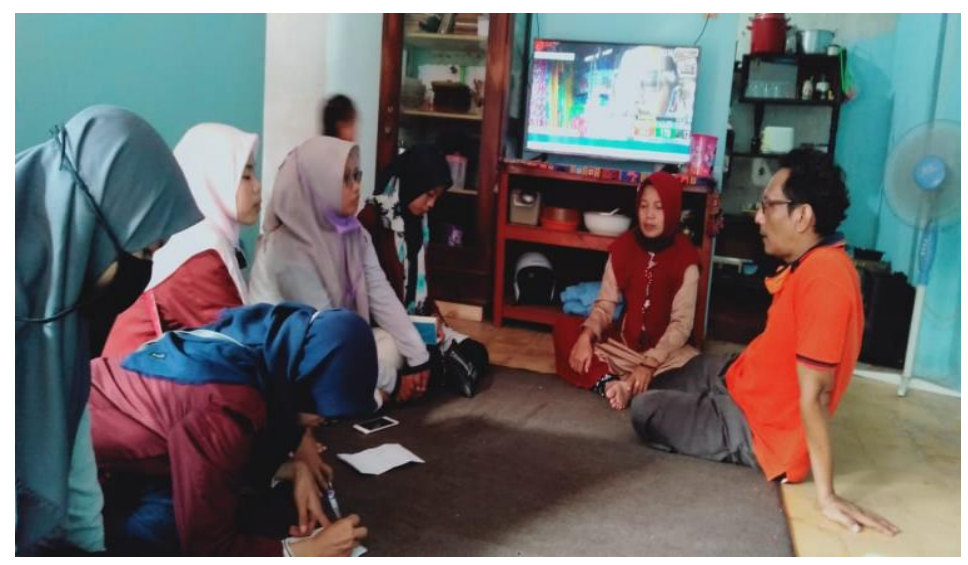

Gambar 3.1: Proses ceramah,tanya jawab,dan tutorial dalam persyaratan dalam pendaftaran surat ijin usaha mikro kecil (I-UMK) dengan salah satu warga Desa Lemahbang.

\section{Small Group Discussion}

Setelah dilakukan ceramah dan tutorial,langkah selanjutnya adalah Metode small group discussion adalah Suatu cara mengajar small group discussion, yaitu metode small group discussion adalah suatu cara mengajar yang dibagi menjadi beberapa kelompok. Setiap kelompok dibagi menjadi tiga sampai dengan lima orang (Fatimah, Kartika, \& Niyartama, 2012).Dalam metode ini tim pengabdian dibagi menjadi tujuh kelompok ke tujuh dusun yang ada di desa lemahbang,setiap kelompok terdapat empat sampai lima orang.Dalam pembagian kelompok tersebut setiap kelompok saling bekerja sama dalam menyelesaikan dan mempesiapkan syarat-syarat yang harus dilengkapi oleh setiap masyarakat yang memiliki usaha mikro kecil dan menengah untuk memperoleh surat ijin usaha mikro kecil ( I-UMK). 


\section{Klyidinatuna \\ Jurnal Penelitian dan Pencabdian Hepada Masularahat}

Institut Agama Islam Sunan Kalijogo Malang

P-ISSN: 2721-9607/ E-ISSN: 2721-947X

Volume 2 Nomor 1 Juli 2021

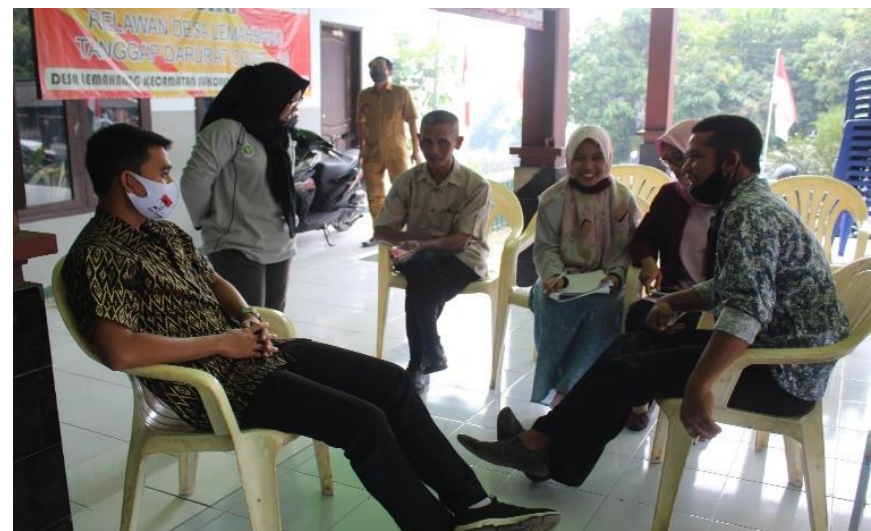

Gambar 3.2: proses small discussioan dengan masyarakat yang memiliki usaha di Dusun Bunder Desa Lemahbang

\section{Komprehensif}

Dalam Komprehensif ini, seluruh kegiatan pengabdian masyarakat ini dilakukan secara serentak di Desa Lemahbang terkait dengan Sumber Daya manusia (SDM),proses belajar, penyuluhan terkait pentingnya legalitas,manfaat dan fungsi I-UMK dan pendampingan legalitas usaha mikro kecil dan menengah dan dibantu pendamping dari dinas perizinan usaha dagang kabupaten Pasuruan yang professional, Kegiatan yang kami laksanakan ini dengan masyarakat yang mengurusi surat ijin usaha mikro kecil untuk memperoleh surat ijin usaha mikro kecil ( I-UMK ) dari dinas perizinan dagang kabupaten Pasuruan.

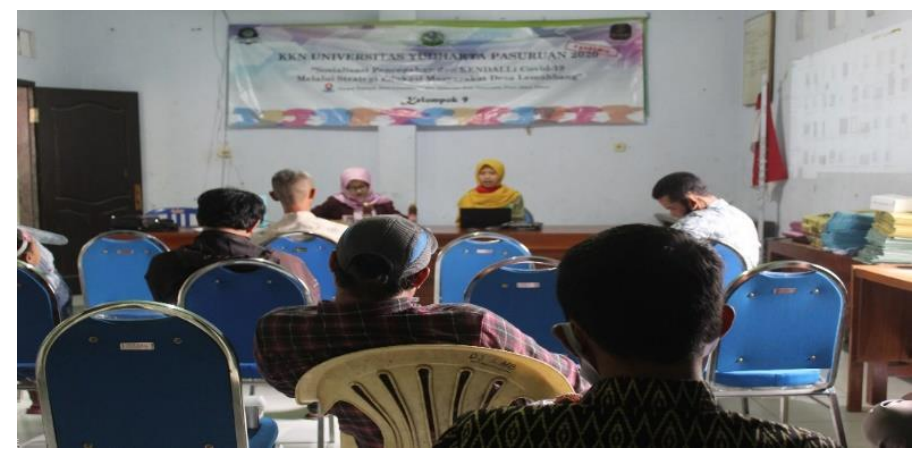

Gambar 3.3 : penyuluhan terkait pentingnya legalitas usaha serta fungsi dan manfaat I-UMK

\section{Learning by Doing Berbasis Output}

Dalam metode learning by doing berbasis output ini dalam pendampingan legalitas usaha mikro kecil dan menengah di Desa Lemahbang yaitu dengan memberikan pehaman terkait dengan pentingnya legalitas usaha mikro kecil dam menengah juga fungsi dan manfaat IUMK,dan menghasilkan output yaitu dengan melakukan proses pendampingan yang 


\section{Khidinatuina \\ Jurnal Penelitian dan Pencabdian Hepada Masularahat}

Institut Agama Islam Sunan Kalijogo Malang

P-ISSN: 2721-9607/ E-ISSN: 2721-947X

Volume 2 Nomor 1 Juli 2021

diharuskan menghasilkan terbitnya I-UMK kepada masing-masing masyarakat yang memiki usaha di Desa Lemahbang yang mengikuti pendampingan yang dilakukan oleh mahasiswa KKN 09 Universitas Yudharta Pasuruan.

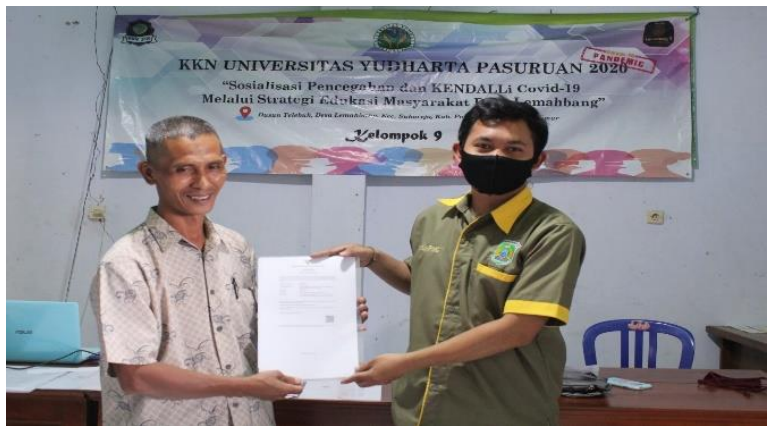

Gambar3. 4:Pembagian Surat ijin usaha mikro kecil (I-UMK) kepada masyarakat yang memiliki usaha.

\section{Ucapan Terimakasih}

Tim KKN 09 Universitas Yudharta Pasuruan Ucapan terimakasih kami kepada bapak kepala desa khususnya bapak kepala Desa Lemahbang, Jombor Atas, Jombor Bawah, Palang, Tambak, Telebuk, Bunder yang telah membantu dan menyukseskan program pendampingan pembuatan surat ijin usaha mikro dan kecil di Desa Lemahbang Kecamatan Sukorejo juga kepada masyarakat Lemahbang yang sudah berkenan menyukseskan program kami.

\section{SIMPULAN}

Program pengabdian masyarakat ini tentang pendampingan pembuatan surat ijin usaha mikro melalui Sistem online single submission (OSS) di Desa Lemahbang, sebagai pemberdayaan ukm di Desa Lemahbang yang belum memiliki surat ijin usaha. Pendampingan dan sosialisasi surat ijin usaha perlu dilakukan untuk para ukm.Bahwa aspek legalitas usaha memberikan kepastian hukum, mendapatkan kemudahan dalam akses pembiyaan ke lembaga keuangan serta mendapatkan perberdayaan dari pemerintah pusat daerah maupun lembaga lainnya. 


\section{Khidinatuna \\ Jurnal Penelitian dan Pencabdian Hepada Masularahat}

Institut Agama Islam Sunan Kalijogo Malang

P-ISSN: 2721-9607/ E-ISSN: 2721-947X

Volume 2 Nomor 1 Juli 2021

\section{DAFTAR PUSTAKA}

Kusmanto Heri dan warjio warjio,2019. Pentingnya legalitas usaha mikro kecil dan menengah. Universitas sumatera utara. Jurnal pendidikan ilmu-ilmu sosial.https://jurnal.unimed.ac.id/2012/index.php/jupiis/article/view/13583

https://www.ukmindonesia.id/baca-izin/1486

https://www.bulelengkab.go.id/detail/artikel/pentingnya-memiliki-izin-usaha-mikro-keciliumk-98

Julita ami, 2017. Pelaksanaan Izin Usaha Mikro Dan Kecil (Iumk) Gratis Di Kecamatan Sukajadi Kota Pekanbaru.Universitas Riau. Jurnal online mahasiswa fakultas ilmu sosial dan ilmu politik universitas riau. http://jom.unri.ac.id/index.php/JOMFSIP/article/view/13728 